\title{
Pterin interactions with distinct reductase activities of NO synthase
}

\author{
Morten M. PANTKE*, Andreas REIF* $\dagger^{+1}$, Juli G. VALTSCHANOFF $\$$, Zhanna SHUTENKO*, Armin FREY*, Richard J. WEINBERG $\$$, \\ Wolfgang PFLEIDERER $\oint$ and Harald H. H. W. SCHMIDT*\| \\ *Department of Pharmacology and Toxicology, Julius-Maximilians-University Würzburg, Versbacher Str. 9, D-97078 Würzburg, Germany, †The Department of \\ Psychiatry and Psychotherapy, Julius-Maximilians-University Würzburg, Füchsleinstr. 15, D-97080 Würzburg, Germany, \$The Department of Cell Biology and Anatomy, \\ University of North Carolina at Chapel Hill, 108 Taylor Hall, Chapel Hill, North Carolina, NC 27599-7400, U.S.A., \$Faculty of Chemistry, University Konstanz, Postfach \\ 5560, D-78434 Konstanz, Germany, and ||Rudolf-Buchheim-Institute for Pharmacology, Justus-Liebig-University Gießen, Frankfurter Str. 107, D-35392 Gießen, Germany
}

Besides oxidizing L-arginine, neuronal NO synthase (NOS) NADPH-dependently reduces various electron acceptors, including cytochrome $c$ and tetrazolium salts. The latter NADPH diaphorase reaction is used as a NOS-specific histochemical stain. Both reductase activities have been utilized to analyse electron transfer mechanisms within NOS. Basal L-arginine turnover by homodimeric NOS is enhanced by exogenous tetrahydrobiopterin, and the intra-subunit electron flow may include intermediate trihydrobiopterin. In the present work we have investigated the possible role of the tetrahydrobiopterin binding site of NOS in its reductase activities by examining the effects of anti-pterin type (PHS) NOS inhibitors. Although the type I anti-pterin, PHS-32, which does not affect basal dimeric NOS activity, also had no effect on either reductase activity, the type II anti-pterin, PHS-72, which inhibits basal NOS activity, inhibited both reductase activities and the NADPH diaphorase histochemical stain. Pterin-free NOS monomers catalysed both cytochrome $c$ and tetrazolium salt reduction. Our data suggest that both NOS reductase activities are independent of tetrahydrobiopterin. However, occupation of an exosite near the pterin site in NOS by type II anti-pterins may interfere with the electron flow within the active centre, suggesting that steric perturbation of the pterin binding pocket or reductase interaction contribute to the mechanism of inhibition by this class of NOS inhibitors.

Key words: anti-pterins, diaphorase, nitric oxide, NO synthase mechanisms, tetrahydrobiopterin.

\section{INTRODUCTION}

Nitric oxide (NO) plays an important role both in physiology, as a signal molecule in the central nervous and cardiovascular systems [1-4], and in pathophysiology, as a cytotoxin in immune and auto-immune responses [5]. NO is generated by three genetically distinct NO synthases (NOS), neuronal (NOS-I), inducible (NOS-II) and endothelial (NOS-III) [6]. All three catalyse the conversion of L-arginine to L-citrulline and $\mathrm{NO}$, $\mathrm{NO}^{-}$(nitroxyl) or related $\mathrm{N}$ oxides [7-9]. However, they exhibit important differences in their modes of expression and activity regulation. NOS-I and NOS-III are constitutively expressed, whereas, in most cells, NOS-II expression requires transcriptional induction, e.g. by cytokines [6]. Enzyme activity of the constitutively expressed isoforms (NOS-I and NOS-III) is stimulated by elevated intracellular levels of free $\mathrm{Ca}^{2+}$ and calmodulin (CaM) [10,11], although some degree of $\mathrm{Ca}^{2+}$-independent activation can be detected upon phosphorylation [12-14]. In contrast, the activity of NOS-II is independent of changes in intracellular free $\mathrm{Ca}^{2+}$, as CaM is tightly bound [15].

NOS is a homodimer, and only the homodimeric conformation of NOS converts L-arginine [16]. Each monomer consists of both a reductase and a mono-oxygenase domain. The reductase domain binds NADPH and, via prosthetic FAD and FMN groups, mediates the transfer of an electron to a catalytically active haem within the oxygenase domain [17]. In addition to
NADPH, FAD and FMN, the intra-subunit electron flow may include intermediate trihydrobiopterin reduction [18]. At the oxygenase domain, the physiological substrate, L-arginine, binds to the enzyme and is oxidized $[19,20]$. The coupling mechanism between the oxygenase and reductase domains is unclear, but is thought to occur close to the pterin binding site [18,21].

One approach to gain insight into the NOS reaction mechanism has been to dissect the overall reaction into partial reactions and to analyse each individually. These reactions include the reduction of molecular oxygen to reactive oxygen species (NADPH oxidase) and the reduction of cytochrome $c$ and tetrazolium salts [e.g. Nitro Blue Tetrazolium (NBT)] [22]. The reduction of NBT (Figure 1) to a water-insoluble formazan, also termed the NADPH diaphorase reaction, is resistant to aldehyde-based protein fixatives and has been used as a histochemical stain for NOS-I in fixed tissue sections [23,24]. Enzyme kinetic analysis of the NBT reductase/NADPH diaphorase activity of NOS has been hampered by the insolubility of the resulting formazan, thus requiring the addition of organic solvents and semiquantitative assay conditions to measure product formation [23,25]. In order to assay the NADPH diaphorase activity of NOS continuously, we developed a method using the tetrazolium salt 5-(3-carboxymethoxyphenyl)-2-(4,5-dimethylthiazolyl)-3-(4-sulphophenyl) tetrazolium (MTS). Reduction of MTS leads to a water-soluble formazan complex and thus does not require organic solvents for spectrophotometric quantification [26,27]. Cytochrome $c$, the

Abbreviations used: CaM, calmodulin; CHAPSO, 3-[(3-cholamidopropyl)-dimethylammonio]-2-hydroxy-1-propanesulphonate; H4 Bip, (6R)-5,6,7,8tetrahydro-L-biopterin; MTS, 5-(3-carboxymethoxyphenyl)-2-(4,5-dimethylthiazolyl)-3-(4-sulphophenyl) tetrazolium salt; NBT, Nitro Blue Tetrazolium; NOS, NO synthase; PHS-72 etc., anti-pterin sub-types; SOD, superoxide dismutase; TEA, triethanolamine.

1 To whom correspondence should be addressed at the Department of Psychiatry and Psychotherapy, Julius-Maximilians-University, Füchsleinstr. 15, D-97080 Würzburg, Germany (e-mail a.reif@gmx.net). 


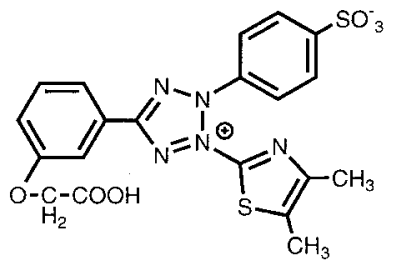

MTS

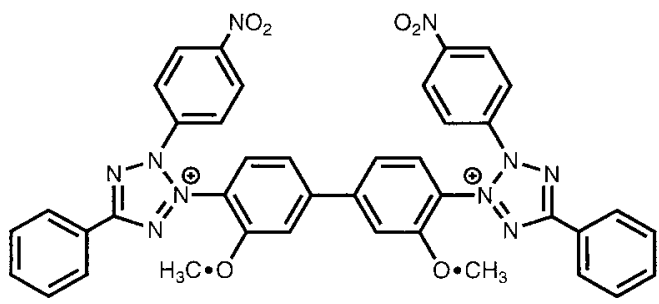

Nitro Blue Tetrazolium (NBT)

Figure 1 NADPH diaphorase substrates of NOS

Chemical structure of the tetrazolium salts MTS, generating a water-soluble formazan, and NBT, generating a water-insoluble formazan.

second reductase substrate, has been shown to bind directly to NOS-I and to be reduced in an NADPH- and $\mathrm{Ca}^{2+} / \mathrm{CaM}-$ dependent manner [22].

Besides NADPH, FAD, FMN and haem, all NOS isoforms require $(6 R)-5,6,7,8$-tetrahydro-L-biopterin $\left(\mathrm{H}_{4} \mathrm{Bip}\right)$ for maximal $\mathrm{L}$-arginine conversion $[28,29]$. The precise function of this redoxactive compound in NOS is not entirely clear; it may act as a radical scavenger to stabilize the active site [30] and play a more direct role within each electron transfer cycle [18]. Since $\mathrm{H}_{4} \mathrm{Bip}$ is not stoichiometrically consumed during L-arginine turnover, the latter hypothesis implies intramolecular pterin reduction and $\mathrm{H}_{4}$ Bip regeneration. Thus the $\mathrm{H}_{4}$ Bip binding site of NOS may be spatially linked to one of the reductase activities of the enzyme. Direct analysis of the role of $\mathrm{H}_{4}$ Bip in this interaction is perturbed by enzyme-independent, chemical interaction of $\mathrm{H}_{4} \mathrm{Bip}$ with the redox-sensitive reductase substrates, e.g. tetrazolium salts. One recent approach to study the role of $\mathrm{H}_{4} \mathrm{Bip}$ in L-arginine turnover and NO synthesis was the utilization of pterin-derived NOS inhibitors [30,31]. These can be divided into two major categories: type I anti-pterins (PHS), such as PHS-32 [30-32], which compete with exogenous $\mathrm{H}_{4} \mathrm{Bip}$, displace endogenous $\mathrm{H}_{4}$ Bip and inhibit NOS to the basal activity observed in the absence of exogenously added $\mathrm{H}_{4} \mathrm{Bip}$, and type II anti-pterins, such as PHS-72 [30-32], which abolish NOS activity completely and bind to NOS without displacing $\mathrm{H}_{4} \mathrm{Bip}$, presumably by binding to the free binding site of the partially $\mathrm{H}_{4}$ Bip-saturated enzyme. Based on molecularfield analysis of their structure-activity relationship and cocrystallization data (H. Matter, P. Kotsonis, C. S. Raman, W. Pfleiderer and H. H. H. W. Schmidt, unpublished work), this is most likely due to their binding to a hydrophobic exosite adjacent to the NOS pterin binding site $[31,32]$. To analyse the NOS pterin binding site and reductase interaction within NOS, we examined the effects of prototypical type I and type II anti-pterins on the reduction of cytochrome $c$ and MTS by purified neuronal NOSI, and compared these results with the possible effects of antipterins on the NADPH diaphorase histochemical stain.

\section{EXPERIMENTAL}

\section{Materials}

NADPH, catalase and $\mathrm{Cu} / \mathrm{Zn}$ superoxide dismutase (SOD) were purchased from Roche Molecular Biochemical (Mannheim, Germany); cytochrome $c, N^{\omega}$-nitro-L-arginine, 3-[(3-cholamidopropyl)-dimethylammonio]-2-hydroxy-1-propanesulphonate (CHAPSO) and triethanolamine hydrochloride (TEA) were from Sigma (Deisenhofen, Germany); $\mathrm{H}_{4}$ Bip was from $\mathrm{Dr}$ Schircks Laboratories (Jona, Switzerland); MTS was from Promega (Madison, WI, U.S.A.); L- $\left[2,3,4,5-{ }^{3} \mathrm{H}\right] \operatorname{arginine} \mathrm{HCl}$ $\left(2.85 \mathrm{TBq} \cdot \mathrm{mmol}^{-1}\right)$ was from Amersham (Braunschweig, Germany); the PhastGel Silver Kit, for silver staining PhastGel SDS/PAGE gels of purified NOS-I, was from Pharmacia Biotech (Freiburg, Germany). All other chemicals were of the highest purity available and obtained from either Sigma or Merck AG (Darmstadt, Germany). Water was deionized to $18 \mathrm{M} \Omega \cdot \mathrm{cm}$ in a Milli-Q apparatus (Millipore, Eschborn, Germany). Anti-pterins were synthesized as described previously $[31,32]$.

\section{Purification of native porcine NOS-I}

Porcine cerebellum NOS-I was prepared as described previously [16,33], with slight modifications [34]. The purification protocol included ammonium sulphate precipitation of a $100000 \mathrm{~g}$ crude supernatant fraction followed by $2^{\prime}, 5^{\prime}$-ADP-Sepharose affinity chromatography. To obtain only the dimeric enzyme, NOS-I was further purified by gel-filtration chromatography. For this step, the eluate from the 2',5'-ADP-Sepharose affinity chromatography (approx. $26 \mathrm{ml}$ ) was concentrated (Centriprep 30; Amicon, Witten, Germany) to approx. $1 \mathrm{ml}$, centrifuged at $10000 \mathrm{~g}$ for $10 \mathrm{~min}$ at $4{ }^{\circ} \mathrm{C}$ and applied to a Superose $6 \mathrm{HR}$ 10/30 gel-filtration column (Pharmacia Biotech, Freiburg, Germany) operated by an FPLC system (Pharmacia Biotech). Gel filtration was performed at $4{ }^{\circ} \mathrm{C}$ at a flow rate of $0.5 \mathrm{ml} \cdot \mathrm{min}^{-1}$ in the presence of a $20 \mathrm{mM} \mathrm{TEA} / \mathrm{HCl}$ buffer $(\mathrm{pH}$ 7.5) containing $0.5 \mathrm{mM}$ EDTA, $150 \mathrm{mM} \mathrm{NaCl}, 10 \%(\mathrm{v} / \mathrm{v})$ glycerol and $0.05 \%$ CHAPSO. Protein was monitored spectrophotometrically at $A_{280}$. NOS-dimer-containing fractions were assayed for L-arginine turnover, and cytochrome $c$ reductase and MTS reductase activities. The purity of NOS-I was determined by SDS/PAGE. Fractions with purity $\geqslant 90 \%$ were pooled, divided into portions and stored at $-80{ }^{\circ} \mathrm{C}$ before use. Pure NOS-I had a specific activity of $268.1 \pm 2.9 \mathrm{nmol}$ citrulline $\cdot \mathrm{mg}^{-1} \cdot \mathrm{min}^{-1}$.

\section{Recombinant human NOS-I}

Recombinant human NOS-I [35] was expressed in a baculovirus/Sf 9 cell system [31], and purified to a specific activity of $643.0 \pm 13.7 \mathrm{nmol}$ of citrulline $\cdot \mathrm{mg}^{-1} \cdot \mathrm{min}^{-1}$ by using $2^{\prime}, 5^{\prime}-\mathrm{ADP}$ Sepharose and CaM-affinity chromatography sequentially, as described previously $[16,35]$.

\section{Synthesis and UV/visible absorption spectra of the MTS-derived formazan}

To establish a quantitative MTS reductase assay, the enzymeindependent, direct chemical reduction of tetrazolium salts by $\mathrm{H}_{4}$ Bip was utilized. Aqueous stock solutions of MTS $(5-50 \mu \mathrm{M})$ were converted to its formazan by adding $\mathrm{H}_{4}$ Bip in a 10 -fold molar excess $(50-500 \mu \mathrm{M})$. Subsequently, the $A_{490}$ of different MTS concentrations was monitored against $\mathrm{H}_{4}$ Bip blanks with a UV/visible spectrophotometer (Hitachi U 2000; Hitachi, Lorch, Germany). An excellent linear correlation between the amount of MTS formazan and absorbance was found over the whole 
concentration range (for three experiments, each performed in triplicate, $\left.r^{2}=0.99\right)$. $A_{490}$ was therefore used to quantify NOScatalysed MTS reduction. Calculations of total formazan were made using a molar absorption coefficient $\left(\epsilon_{490}\right)$ of $2.52 \pm$ $1.4 \times 10^{4} \mathrm{M}^{-1} \cdot \mathrm{cm}^{-1}$.

\section{MTS reductase assay}

MTS was freshly dissolved in $50 \mathrm{mM}$ TEA/ $\mathrm{HCl}$ buffer ( $\mathrm{pH} 7.0$ ). These MTS stock solutions were protected from light and kept on ice for immediate use. MTS reductase activity was assayed in 96-well microtitre plates by measuring the NOS-catalysed reduction of $2 \mathrm{mM}$ MTS to its water-soluble formazan in a $100 \mu \mathrm{l}$ reaction volume containing $0.1 \mathrm{mM}$ NADPH in $50 \mathrm{mM}$ TEA/ $\mathrm{HCl}$ buffer $(\mathrm{pH}$ 7.0). Reactions were started by the addition of 70-80 ng of purified NOS-I. After an incubation period of $15 \mathrm{~min}$ at $37^{\circ} \mathrm{C}$, with protection from light, the $A_{490}$ was measured using a ThermoMax Microplate Reader (Molecular Devices, Menlo Park, CA, U.S.A.). Blanks for each concentration of MTS were measured in the absence of enzyme and subsequently subtracted from the values obtained in the presence of NOS.

\section{Cytochrome $c$ reductase assay}

Determination of cytochrome $c$ reductase activity was modified from a method described previously [22]. Stock solutions of cytochrome $c$ and NADPH were freshly made on the day of use. Cytochrome $c$ turnover was measured spectrophotometrically by the NOS-catalysed reduction of $0.2 \mathrm{mM}$ cytochrome $c$ in $100 \mu \mathrm{l}$ of $50 \mathrm{mM}$ TEA/HCl buffer (pH 7.0) containing $100 \mu \mathrm{M} \mathrm{CaCl}_{2}$, $100 \mathrm{nM}$ CaM and $0.1 \mathrm{mM}$ NADPH. Reactions were started by the addition of $70-80 \mathrm{ng}$ of purified NOS and continued at $37^{\circ} \mathrm{C}$ for $25 \mathrm{~min}$. The total amount of reduced cytochrome $c$ was calculated using a molar absorption coefficient $\left(\epsilon_{550}\right)$ of $2.1 \times$ $10^{4} \mathrm{M}^{-1} \cdot \mathrm{cm}^{-1}$.

\section{Determination of L-arginine turnover}

NOS-catalysed L-arginine turnover was determined by measuring L- $\left[{ }^{3} \mathrm{H}\right]$ citrulline production from $\mathrm{L}-\left[{ }^{3} \mathrm{H}\right]$ arginine as described previously [36], with modifications [34]. Assays were performed in a reaction mixture containing $50 \mathrm{mM}$ TEA/HCl buffer $(\mathrm{pH} 7.5)$, $20 \mu \mathrm{M}$ L-arginine (including $5.55 \mathrm{kBq} \mathrm{L}-\left[2,3,4,5-{ }^{3} \mathrm{H}\right]$ arginine), $1 \mathrm{mM}$ NADPH, $5 \mu \mathrm{M}$ FAD, $10 \mu \mathrm{M}$ FMN, $50 \mathrm{nM}$ CaM, $1 \mathrm{mM}$ $\mathrm{CaCl}_{2}$ and $2 \mu \mathrm{M} \mathrm{H}_{4}$ Bip. Blank values were determined in the absence of enzyme. Incubations were performed at $37^{\circ} \mathrm{C}$ for $15 \mathrm{~min}$. The reaction was terminated by addition of stop buffer containing $20 \mathrm{mM}$ sodium acetate (pH 5.5) and $2 \mathrm{mM}$ EDTA at $4{ }^{\circ} \mathrm{C}$. $\left[{ }^{3} \mathrm{H}\right]$ Citrulline, and thus total $\mathrm{L}$-arginine to L-citrulline conversion, was subsequently measured by liquid scintillation spectroscopy as described previously [31].

\section{Generation and separation of NOS monomers and dimers}

Under native conditions, L-arginine conversion in the absence of $\mathrm{H}_{4}$ Bip leads to NOS monomerization. NOS monomers and dimers can then be separated by size-exclusion chromatography and investigated further [30]. To generate NOS monomers, homodimeric recombinant human NOS-I $(17 \mu \mathrm{g})$ was preincubated at $\mathrm{pH} 7.0$ in the presence of $25 \mathrm{mM}$ L-arginine, $1 \mathrm{mM}$ NADPH, $5 \mu \mathrm{M}$ FAD, $10 \mu \mathrm{M}$ FMN, $500 \mathrm{nM} \mathrm{CaM}, 1 \mathrm{mM} \mathrm{CaCl}{ }_{2}$, $250 \mu \mathrm{M}$ CHAPSO and $0.5 \mathrm{M}$ TEA $/ \mathrm{HCl}$. The final incubation volume was $100 \mu \mathrm{l}$. Incubations were carried out at $37^{\circ} \mathrm{C}$ for $15 \mathrm{~min}$ and stopped by the addition of $10 \mu \mathrm{l}$ of ice-cold $5 \mathrm{mM}$ EGTA. Immediately thereafter, samples were mixed, frozen in liquid nitrogen and stored at $-80{ }^{\circ} \mathrm{C}$. After thawing, samples were centrifuged at $10000 \mathrm{~g}$ for $10 \mathrm{~min}$ at $4{ }^{\circ} \mathrm{C}$, and analysed by Superose $6 \mathrm{HR} 10 / 30$ size-exclusion chromatography as described previously [30,31]. NOS dimers were eluted at $12.58 \pm 0.05 \mathrm{ml}$, monomers at $14.09 \pm 0.06 \mathrm{ml}$, corresponding to Stokes' radii of $7.89 \pm 0.01 \mathrm{~nm}$ and $6.07 \pm 0.06 \mathrm{~nm}$, which was in agreement with published values [16]. The two eluates were divided into aliquots of $300 \mu \mathrm{l}$, which contained purely dimeric or monomeric NOS.

\section{NADPH diaphorase histochemical stain}

Sprague-Dawley rats were anaesthetized and perfused intraaortically with mixed aldehyde fixatives. Vibratome sections of the spinal cord, 25-50 $\mu \mathrm{m}$ thick, were incubated for $15 \mathrm{~min}$ in the presence of either $200 \mu \mathrm{M}$ anti-pterin dissolved in DMSO or vehicle alone for control experiments. NADPH diaphorase staining was performed as described previously [24,37,38]. Sections were incubated at $37^{\circ} \mathrm{C}$ for $1.5 \mathrm{~h}$ in a mixture of $0.1 \%$ (w/v) NADPH, $0.02 \%(\mathrm{w} / \mathrm{v})$ NBT and $0.3 \%(\mathrm{v} / \mathrm{v})$ Triton X100 in phosphate buffer ( $\mathrm{pH}$ 7.4). Staining, using this protocol, co-localizes with immunocytochemically-defined NOS-I $[24,37,38]$ and concentrates in lamina II-III of the superficial dorsal horn of the spinal cord [39-42].

\section{Determination of protein}

Protein concentrations were determined according to Bradford [43] using BSA as a standard.

\section{Statistics}

All results are expressed as means \pm S.E.M.. Non-linear regression analysis was performed using the Prism 2.0 software package (GraphPad, San Diego, CA, U.S.A.).

\section{RESULTS}

\section{Characterization of MTS and cytochrome $c$ reductase activities}

To establish MTS reductase as a novel on-line assay for the NADPH diaphorase activity of NOS, we examined the ability of native porcine NOS-I to reduce MTS. The NADPH dependency of this activity was then characterized in comparison with the established cytochrome $c$ reductase and L-arginine-to-citrulline activities of NOS.

Purified porcine cerebellum NOS-I $(0.6 \mu \mathrm{g})$, in the presence of $1 \mathrm{mM}$ NADPH, was incubated with increasing concentrations of MTS $(10 \mu \mathrm{M}-3.2 \mathrm{mM})$, as described in the Experimental section, and the $A_{490}$ was measured after $30 \mathrm{~min}$ of incubation at $37^{\circ} \mathrm{C}$. The data were fitted to a sigmoidal concentration-response curve (results of four individual experiments performed in triplicate; $r^{2}=0.99$ ), which indicated the saturable, enzymic formation of formazan. NOS-I thus reduced MTS to a watersoluble formazan complex in a concentration-dependent manner with a $K_{\mathrm{m}}$ [MTS] value of $600.8 \pm 1.1 \mu \mathrm{M}$ and a specific activity $\left(V_{\max }\right)$ of up to $1.8 \mu \mathrm{mol} \mathrm{mg}^{-1} \cdot \mathrm{min}^{-1}$.

Thereafter, NOS-I was assayed for MTS (50 ng of NOS-I) and cytochrome $c$ (75 ng of NOS-I) reductase activities. Reductase activities, at $37^{\circ} \mathrm{C}$, were monitored over $30 \mathrm{~min}$ at $1 \mathrm{~min}$ intervals and total amounts of formazan and reduced cytochrome $c$ were calculated. Linear regression analysis was performed for three experiments, each performed in triplicate. MTS reductase activity remained stable over a period of $15 \mathrm{~min}$, and declined thereafter; cytochrome $c$ turnover was linear for at least $30 \mathrm{~min}$. The kinetics of MTS turnover thus resembled those of L-arginine turnover, which is also linear for approx. 15 min under similar conditions. 


\section{Table 1 Comparison of distinct NOS activities}

L-Citrulline formation, MTS reduction and cytochrome $c$ reduction by purified porcine cerebellum NOS-I were determined, as described in the Experimental section, in the presence of various concentrations of NADPH and CaM. Subsequently, non-linear regression analysis was performed to calculate $K_{\mathrm{a}}$ or $K_{\mathrm{m}}$ values. All activities were NADPH-dependent; however, only cytochrome $c$ and citrulline formation were enhanced by the addition of $\mathrm{Ca}^{2+} / \mathrm{CaM}$.

\begin{tabular}{lccl}
\hline & $K_{\mathrm{m}} \mathrm{NADPH}(\mu \mathrm{M})$ & $\mathrm{EC}_{50} \mathrm{CaM}(\mathrm{nM})$ & $V_{\max }\left(\mathrm{nmol} \cdot \mathrm{min}^{-1} \cdot \mathrm{mg}^{-1}\right)$ \\
\hline Citrulline formation & $10.3 \pm 3.2$ & $5.3 \pm 1.5$ & $268 \pm 3$ \\
MTS reduction & $20.9 \pm 1.7$ & No dependence & $1370 \pm 170$ \\
Cytochrome $c$ reduction & $9.9 \pm 6.4$ & $14.1 \pm 1.2$ & $5489 \pm 213$ \\
& & &
\end{tabular}

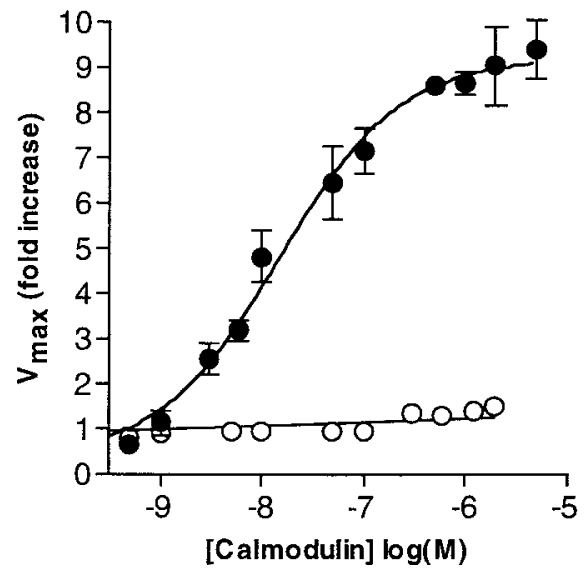

Figure 2 Effects of CaM on cytochrome $c$ and MTS reductase activities of NOS-I

Purified porcine cerebellum NOS-I (140 ng) was incubated in the absence or presence of CaM $(0.1 \mathrm{nM}-2 \mu \mathrm{M})$ with either cytochrome $c(\mathbf{O})$ or MTS $(\bigcirc)$. All other assay conditions were the same as described in the Experimental section. Control values were determined in the absence of CaM. Each value represents the mean \pm S.E.M. of three individual experiments, each performed in triplicate. The effects of increasing concentrations of $\mathrm{Ca}^{2+} / \mathrm{CaM}$ on cytochrome $c$ reductase activity were analysed by fitting a sigmoidal concentration response curve to the data points $\left(r^{2}=0.99\right)$. Cytochrome $c$ reduction by NOS-I was found to be greatly enhanced by $\mathrm{Ca}^{2+} / \mathrm{CaM}$ in a concentration-dependent manner, whereas the formation of MTS-derived formazan was not significantly affected.

To further characterize the MTS reductase assay, we determined the apparent $K_{\mathrm{m}}$ value for NADPH and compared it with the respective value in the cytochrome $c$ assay. NOS-I $(140 \mathrm{ng})$ was incubated with MTS or cytochrome $c$, as described in the Experimental section, with increasing concentrations of NADPH (100 nM-10 mM). Both MTS and cytochrome $c$ reductase activities were NADPH-dependent with $K_{\mathrm{m}}$ [NADPH] values in the same range as for L-arginine turnover (Table 1). Non-linear regression analysis was performed and resulted in a sigmoidal concentration response curve for both MTS $\left(r^{2}=\right.$ $0.98)$ and cytochrome $c$ turnover $\left(r^{2}=0.98\right)$.

\section{$\mathrm{Ca}^{2+} / \mathrm{CaM}$ was without effect on MTS turnover, but stimulated cytochrome $c$ reduction}

MTS reductase activity was independent of $\mathrm{CaM}$ in the range of $0.1 \mathrm{nM}$ to $2 \mu \mathrm{M}$, in the presence of saturating $\mathrm{Ca}^{2+}$ concentrations (Figure 2). Conversely, cytochrome $c$ reductase activity was largely dependent on $\mathrm{Ca}^{2+} / \mathrm{CaM}$ (Figure 2), which stimulated basal cytochrome $c$ reduction approx. 9-fold. The half-maximally effective concentration $\left(\mathrm{EC}_{50}\right)$ of $\mathrm{CaM}$ for stimulating cyto-
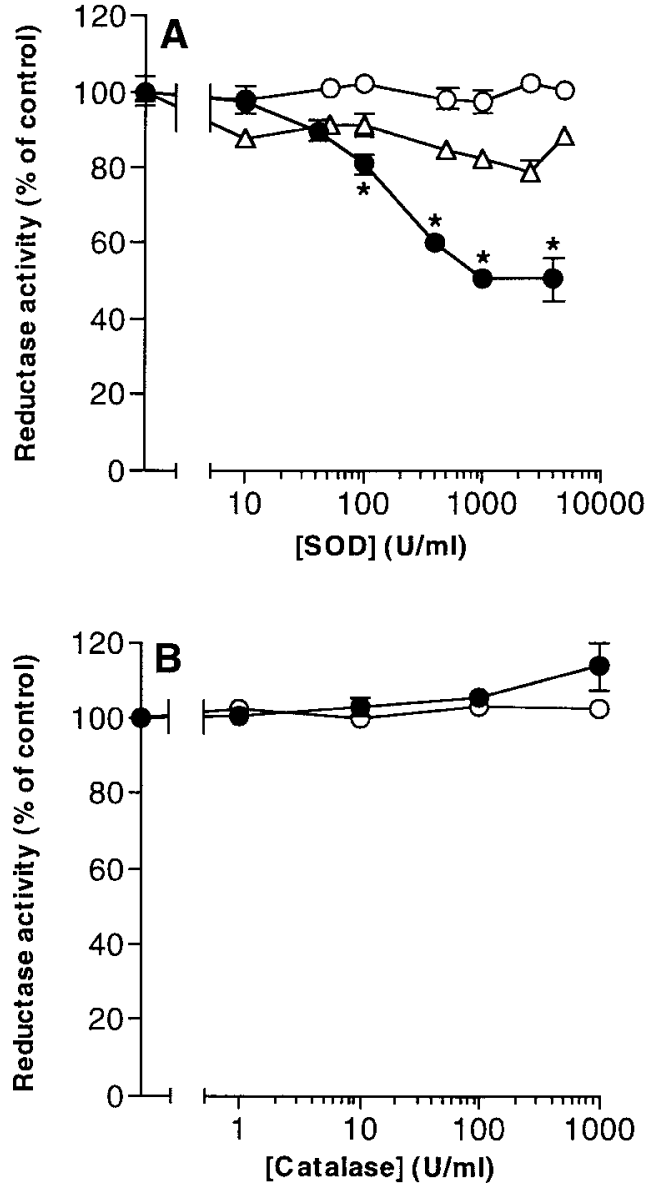

Figure 3 Effect of SOD and catalase on cytochrome $c$ and MTS reductase activity of NOS-I

(A) Cytochrome $c\left(\mathrm{O}\right.$, in the presence of $100 \mu \mathrm{M} \mathrm{CaCl}_{2}$ and $100 \mathrm{nM} \mathrm{CaM}$; $\mathbf{O}$, in the absence of $\left.\mathrm{Ca}^{2+} / \mathrm{CaM}\right)$ and MTS $(\triangle)$ reductase activities were determined in the presence of purified porcine cerebellum NOS-I (115 ng) and increasing concentrations of SOD [10-5000 units (U) $\cdot \mathrm{ml}^{-1}$ ]. MTS reduction was found to be significantly inhibited by SOD, whereas cytochrome $c$ turnover was affected neither in the presence nor in the absence of $\mathrm{Ca}^{2+} / \mathrm{CaM}$. (B) Cytochrome $c\left(\mathrm{O}\right.$, in the presence of $100 \mu \mathrm{M} \mathrm{CaCl}_{2}$ and $\left.100 \mathrm{nM} \mathrm{CaM}\right)$ and MTS reductase (-) activities were determined as above, but in the presence of increasing concentrations of catalase $\left(0.1-1000\right.$ units $\left.\cdot \mathrm{ml}^{-1}\right)$ instead of SOD. No effect of catalase was observed on cytochrome $c$ or on MTS reduction, arguing against a role for $\mathrm{H}_{2} \mathrm{O}_{2}$ in the reductase activities of NOS-I. All other assay conditions were the same as described in the Experimental section. Activity is expressed as a percentage of the respective control, e.g. in the presence of $\mathrm{Ca}^{2+} / \mathrm{CaM}$, and in the absence of SOD or catalase. Data points represent means \pm S.E.M. of three individual experiments, each performed in triplicate. The asterisk ( $\left(^{\star}\right)$ indicates significant difference from the respective control, $P<0.01$.

chrome $c$ reduction by NOS was similar to its $\mathrm{EC}_{50}$ value for stimulating citrulline formation (Table 1).

\section{Effects of SOD on MTS and cytochrome $c$ reductase activities}

The extend to which NOS reductase activities are mediated by intermediate superoxide $\left(\mathrm{O}_{2}^{-}\right)$formation is controversial $[44,45]$. To address this issue, the effects of SOD on MTS and cytochrome $c$ reductase activities of native porcine NOS-I were investigated. SOD inhibited MTS reduction at concentrations as low as 100 units $\cdot \mathrm{ml}^{-1}$. At 1000 units $\cdot \mathrm{ml}^{-1}$, inhibition by SOD was maximal $(50 \%$ of control). In contrast, even the highest concentration of SOD tested ( $5 \mathrm{k}$-units $\left.\cdot \mathrm{ml}^{-1}\right)$ had no effect on the $\mathrm{Ca}^{2+} / \mathrm{CaM}$-stimulated reduction of cytochrome $c$ (Figure 3A). 

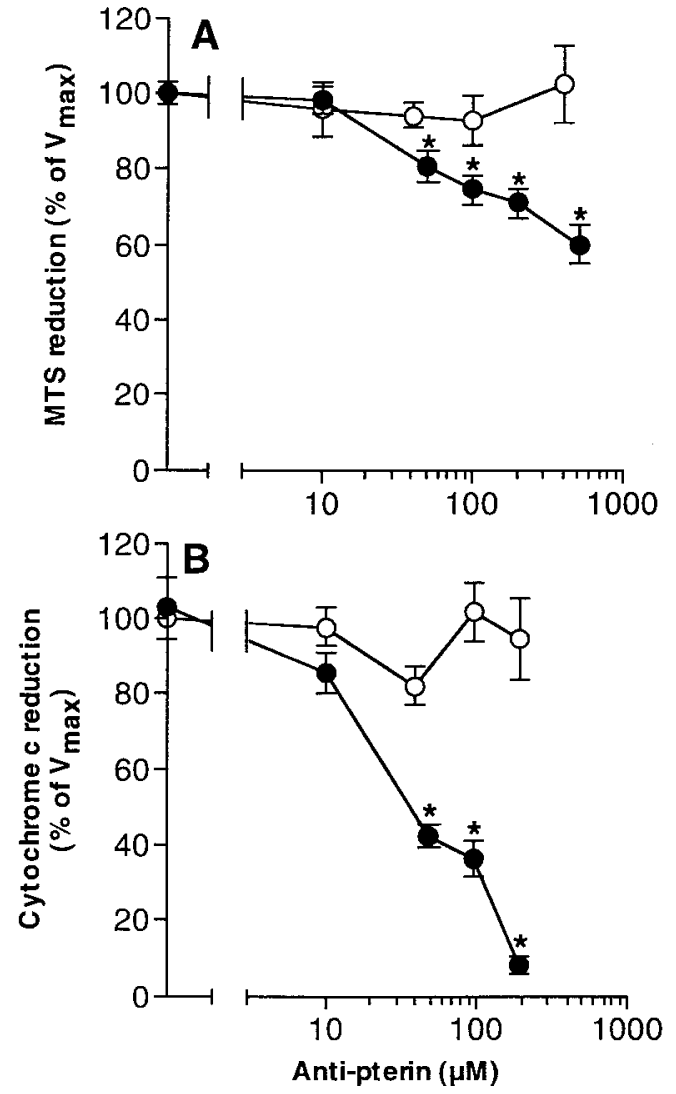

Figure 4 Effect of type I and II anti-pterins on MTS and cytochrome $c$ reductase activities of purified porcine NOS-I

(A) Purified porcine cerebellum NOS-I (70 ng) was incubated in the presence of MTS (2 mM), NADPH $(0.1 \mathrm{mM})$, and various concentrations of PHS-32 $(\mathrm{O})$ or PHS-72 $(\mathbf{)})$. The type II antipterin PHS-72 significantly inhibited MTS reductase activity, whereas the type I anti-pterin PHS32 had no effect. Control values were determined in the absence of anti-pterins and in the presence of NOS and solvent (10\% DMSO). The activity of the samples is expressed as a percentage of the respective control. Data points represent means \pm S.E.M. of three individual experiments, each performed in triplicate. (B) Purified porcine cerebellum NOS-I $(70 \mathrm{ng})$ was incubated in the presence of cytochrome $c(0.2 \mathrm{mM})$, NADPH $(0.1 \mathrm{mM}), \mathrm{CaCl}_{2}(100 \mu \mathrm{M}), \mathrm{CaM}$ $(100 \mathrm{nM})$ and various concentrations of PHS-32 $(\mathrm{O})$ or PHS-72 $(\boldsymbol{)})$. The anti-pterin II PHS72 significantly inhibited cytochrome $c$ reductase activity of NOS-I, whereas the anti-pterin PHS-32 had no effect. Except for the addition of DMSO and anti-pterins, assay conditions were as described in the Experimental section. Controls contained enzyme and solvent (10\% DMSO), but no anti-pterins. Activity is reported as a percentage of $V_{\max }$. Data points represent means \pm S.E.M. of three experiments, each performed in triplicate. The asterisk $\left(^{*}\right)$ indicates significant difference from control, $P<0.001$

Since a portion of cytochrome $c$ reduction is CaM-independent, we also characterized this basal activity. However, up to $5 \mathrm{k}-$ units $\cdot \mathrm{ml}^{-1}$ SOD had no effect on cytochrome $c$ reduction, regardless of whether $\mathrm{Ca}^{2+} / \mathrm{CaM}$ was present or not, suggesting that neither basal nor CaM-stimulated reduction of cytochrome $c$ is mediated by $\mathrm{O}_{2}^{-}$(Figure $3 \mathrm{~A}$ ).

\section{Catalase affects neither MTS nor cytochrome $c$ reduction}

Instead of intermediate $\mathrm{O}_{2}^{-}$, NOS may also form $\mathrm{H}_{2} \mathrm{O}_{2}$ (A. Reif, Z. Shutenko, M. Feelisch and H. H. H. W. Schmidt, unpublished work), which may interfere with MTS or cytochrome $c$ reduction. Therefore the effects of various concentrations of catalase (0.1-1000 units $\left.\cdot \mathrm{ml}^{-1}\right)$ on MTS and cytochrome $c$ reductase activities were examined. However, catalase affected neither MTS nor cytochrome $c$ reduction (Figure 3B). Thus the lack of

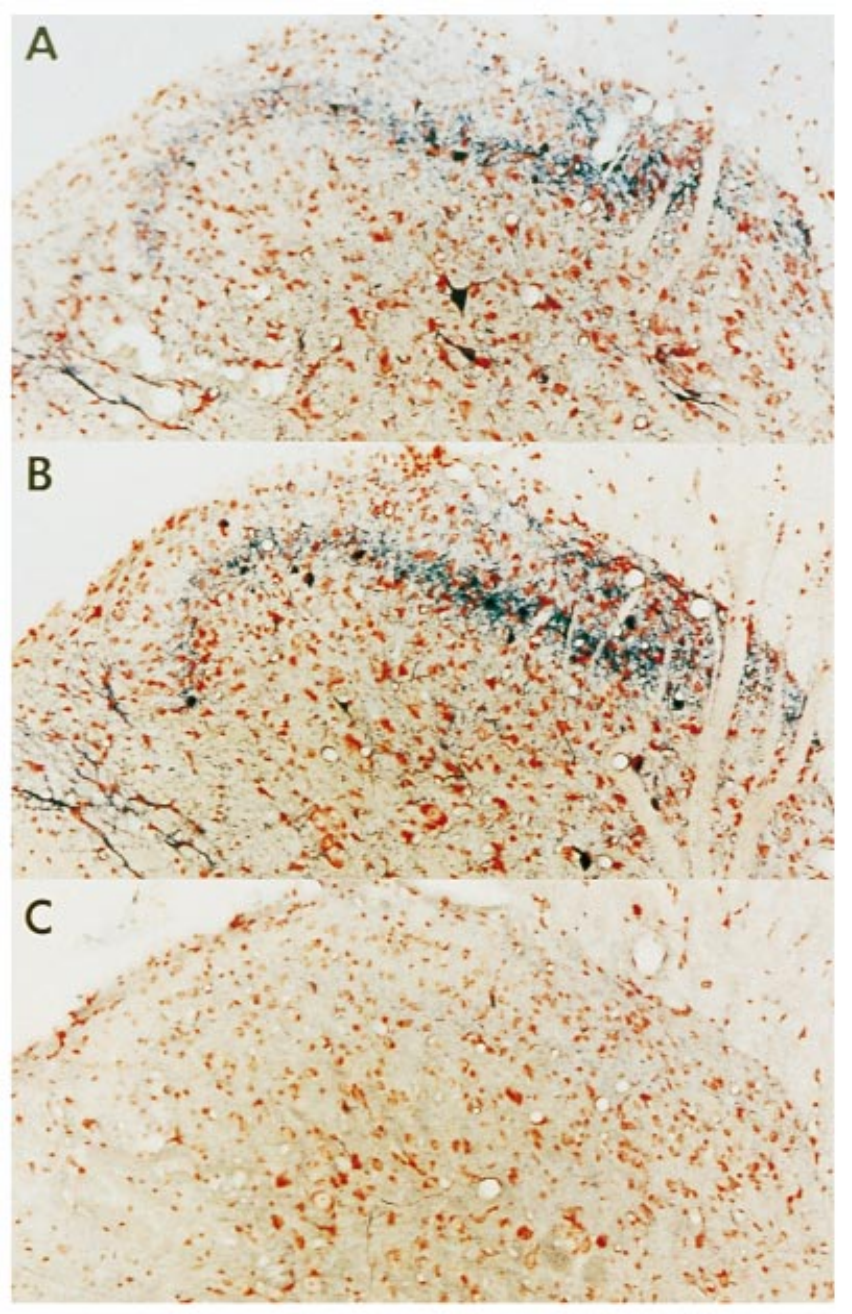

Figure 5 Effect of anti-pterins on NADPH diaphorase histochemical stain

Vibratome sections of rat spinal cord, known to contain high levels of neuronal NO synthase (NOS-I), were processed for NADPH diaphorase activity, as described in the Experimental section, after incubation with $200 \mu \mathrm{M}$ anti-pterin or vehicle. Control staining (A) without antipterin was concentrated in laminae II-III of the dorsal horn. Preincubation of sections with $200 \mu \mathrm{M}$ PHS-32 (B) showed the same staining pattern as the control, whereas pre-treatment with $200 \mu$ M PHS-72 (C) markedly inhibited NADPH diaphorase staining. Data are representative of three independent experiments.

effect of SOD on the cytochrome $c$ reductase of NOS cannot be explained by intermediate $\mathrm{H}_{2} \mathrm{O}_{2}$ formation.

\section{Effects of anti-pterins on MTS and cytochrome $\boldsymbol{c}$ reduction}

To investigate the possible role of NOS-associated $\mathrm{H}_{4}$ Bip or the NOS pterin binding site for the two NOS reductase activities studied, we examined the effect of one prototypic compound for each of the two classes of anti-pterin on MTS and cytochrome $c$ reduction. Figure 4(A) shows the effect of type I (PHS-32) and type II (PHS-72) anti-pterins on MTS reductase activity of native NOS-I, expressed as a percentage of the control, i.e. without added anti-pterin. PHS-32 had no effect on MTS turnover in concentrations of up to $400 \mu \mathrm{M}$. Conversely, PHS-72 induced a significant, concentration-dependent inhibition of formazan formation down to $60 \%$ of control. 
Table 2 Expression of MTS and cytochrome $c$ reductase activity by both pterin-containing dimers and pterin-free monomers

Recombinant human NOS-I (17 $\mu \mathrm{g})$ was separated into pterin-containing dimers and pterin-free monomers by size-exclusion chromatography as described in the Experimental section. Subsequently, $40 \mu \mathrm{l}$ (L-arginine conversion, cytochrome $c$ reduction) and $50 \mu \mathrm{l}$ (MTS reduction) of the same dimer and monomer peak fractions were assayed for citrulline formation, MTS and cytochrome $c$ reductase activities as described in the Experimental section. The values represent absolute amounts of product formed $\cdot \mathrm{min}^{-1} \cdot \mathrm{ml}^{-1}$; n.d., not detectable.

\begin{tabular}{llc}
\hline & Monomeric NOS-I & Dimeric NOS-I \\
\hline Citrulline formation (pmol) & n.d. & $19.3 \pm 0.1$ \\
MTS reduction $(\mathrm{pmol})$ & $1850 \pm 270$ & $2000 \pm 130$ \\
Cytochrome $c$ reduction $(\mathrm{pmol})$ & $8620 \pm 100$ & $8580 \pm 300$
\end{tabular}

The effects of the same anti-pterins on cytochrome $c$ reductase activity of native porcine NOS-I are shown in Figure 4. Similarly to MTS reduction, the type I PHS-32, in concentrations of up to $200 \mu \mathrm{M}$, had no significant effect on cytochrome $c$ reduction. In contrast, the type II PHS-72 significantly decreased cytochrome $c$ turnover in a concentration-dependent manner. At $200 \mu \mathrm{M}$, this compound diminished cytochrome $c$ reduction to $8 \%$ of the control value. These data suggest a selective inhibitory effect of type II anti-pterins, which occupy not only the NOS pterin binding site in a $\mathrm{H}_{4}$ Bip-competitive manner, but also an adjacent, hydrophobic exosite. The latter is not competitive with $\mathrm{H}_{4}$ Bip, and may interfere sterically with subdomain interactions, e.g. oxygenase/reductase coupling.

\section{The effects of anti-pterins are preserved in the NADPH diaphorase histochemical stain}

An assay in vitro for NADPH diaphorase activity of neuronal NOS using MTS can only be an approximation of the reactions which occur during the NADPH diaphorase histochemical staining procedure using NBT. Therefore we investigated the effects of the different anti-pterins on NADPH diaphorase stains with NBT in neuronal tissue sections (Figure 5). Staining in the absence of anti-pterins (Figure 5A) was concentrated in lamina II-III of the superficial dorsal horn. In the presence of $200 \mu \mathrm{M}$ of type I PHS-32 (Figure 5B), the NADPH diaphorase stain remained unaffected, showing the same staining pattern as the control sections (Figure 5A). However, $200 \mu \mathrm{M}$ of the type II PHS-72 (Figure 5C) almost abolished NADPH diaphorase activity staining in the tissue sections. These findings are consistent with the data derived from the MTS assay in vitro, and strengthen the hypothesis that MTS is a substrate for the NADPH diaphorase reaction and that this activity is selectively altered by the type II PHS-72.

\section{Both pterin-containing dimers and pterin-free monomers of NOS-I have MTS and cytochrome $c$ reductase activity}

$\mathrm{H}_{4}$ Bip is also involved in NOS dimer stabilization [30], but present data do not allow differentiation of the possible roles for $\mathrm{H}_{4} \mathrm{Bip}$ in MTS and cytochrome $c$ reductase activities in dimeric and monomeric NOS-I. Thus recombinant human NOS-I was separated into pterin-containing dimers $\left(6.13 \pm 0.39\right.$ pmol $\mathrm{H}_{4} \mathrm{Bip}$ per fraction) and pterin-free monomers. Both states of NOS, dimeric and monomeric, occur during NOS-catalysed L-arginine turnover [30] or can be generated in the presence of various protein denaturants, such as SDS [46] or urea [47]. However, both NOS-I dimers and monomers were competent for MTS and cytochrome $c$ turnover (Table 2), suggesting that these NOS activities are pterin-independent but are affected by pterin exosite occupation by the type II PHS-72.

As we observed cytochrome $c$ turnover by monomeric NOS, we investigated whether NOS monomers also required $\mathrm{Ca}^{2+} /$ $\mathrm{CaM}$ to reduce cytochrome c. We therefore incubated monomeric NOS, as described above, with and without $\mathrm{CaCl}_{2}(100 \mu \mathrm{M})$ and $\mathrm{CaM}(100 \mathrm{nM})$. In the absence of both $\mathrm{Ca}^{2+}$ and $\mathrm{CaM}$, only $24.89 \pm 2.42 \%$ of the $V_{\max }$, i.e. the activity in the presence of $\mathrm{Ca}^{2+}$ and $\mathrm{CaM}$, was observed in three experiments, each performed in triplicate. The electron flow to the haem in monomeric NOS therefore also appears to be regulated by $\mathrm{CaM}$.

\section{DISCUSSION}

In addition to L-arginine oxidation, NOS NADPH-dependently reduces artificial electron acceptors such as tetrazolium salts [23], cytochrome $c$ [22] and others [45]. The reduction of the tetrazolium salt NBT to a water-insoluble formazan complex, termed the NADPH diaphorase reaction, is widely used as a selective histochemical marker for NOS-I in aldehyde-fixed sections of neuronal and other tissues $[23,48,49]$. Yet it is mechanistically not understood which domain in NOS mediates this reaction.

In the present work, we demonstrate that purified porcine cerebellar NOS also reduces the tetrazolium salt MTS. Using MTS as an electron acceptor to quantify NADPH diaphorase activity has the advantage of forming a water-soluble formazan complex, which allows enzyme kinetic analysis. NOS-dependent formation of MTS formazan mirrored the kinetics of L-arginine to L-citrulline conversion [34]. Similarly to the reduction of NBT, MTS turnover showed an absolute requirement for NADPH. As both substrates are tetrazolium salts, MTS can be considered as an alternative substrate for the NADPH diaphorase activity of NOS-I. This is corroborated by the qualitatively similar inhibition pattern of anti-pterins on all three reductase activities, cytochrome $c$ reductase MTS reductase and NADPH diaphorase.

Calmodulin triggers the flavin-to-haem electron transfer between the reductase and oxygenase domains of the enzyme [50], increases the rate of electron transfer into the flavins [51], and is therefore essential for maximal L-arginine-to-L-citrulline conversion. The reduction of cytochrome $c$, but not that of MTS, was enhanced by $\mathrm{CaM}$ in a concentration-dependent manner. This profound difference in $\mathrm{Ca}^{2+} / \mathrm{CaM}$-mediated catalysis of MTS and cytochrome $c$ emphasizes the important and specific role of CaM binding between the haem and flavin-binding domains of all NOSs. Calmodulin presumably affects the orientation of these domains, thereby modulating and de-inhibiting [45] electronic coupling of the reductase-to-oxygenase domain.

In contrast, the effects of $\mathrm{Ca}^{2+} / \mathrm{CaM}$ on the NADPH diaphorase activity of NOS remain unclear. NBT formazan formation is generally believed to be $\mathrm{Ca}^{2+} / \mathrm{CaM}$-independent, although one report found it to be increased by $\mathrm{Ca}^{2+} / \mathrm{CaM}$ [44]. In our hands, MTS reduction was independent of $\mathrm{Ca}^{2+} / \mathrm{CaM}$, consistent with most other reports [25]. The possibility exists that enzyme-bound $\mathrm{H}_{4}$ Bip is oxidized by MTS (see the Experimental section), thus influencing the $\mathrm{CaM}$ sensitivity of the enzyme. However, this would imply an interference in the $\mathrm{H}_{4} \mathrm{Bip}$ and the $\mathrm{CaM}$ binding sites, which has not been observed experimentally [52]. Furthermore, NOS is only partially saturated with endogenously bound $\mathrm{H}_{4}$ Bip [30,31], so that changes in the $\mathrm{H}_{4} \mathrm{Bip}$ redox state should only affect a sub-fraction of purified enzyme. Thus $\mathrm{H}_{4}$ Bip oxidation is unlikely to account for the observed differences in the CaM dependence between MTS and cytochrome $c$ reductase activities.

It has been shown that $\mathrm{Ca}^{2+} / \mathrm{CaM}$ increases cytochrome $c$ reduction by NOS up to $10-15$ fold, whereas it stimulates the rate 
of reduction of the artificial electron acceptors 2,6-dichlorophenolindophenol and ferricyanide only slightly or not at all [45]. This is in good agreement with our present data on both the CaM-dependence of cytochrome $c$ reduction and the CaMindependence of MTS reduction. Since the formation of Lcitrulline from L-arginine is CaM-dependent, cytochrome $c$ reduction appears to follow a similar mode of electron transfer, despite the fact that direct protein-protein interaction occurs [22]. Moreover, a variety of electron acceptors (natural and artificial) interfere with NO formation, because of the low substrate specificity of the reductase domain of NOS [22]. Presumably, due to competition with molecular oxygen for NADPH-derived electrons, these acceptor molecules inhibit Lcitrulline formation in a concentration-dependent manner $[23,44]$.

The role of intermediate superoxide for the cytochrome $c$ reductase activity of NOS-I, in addition to direct protein-protein interaction, remains a matter of debate $[44,45] . \mathrm{Ca}^{2+} / \mathrm{CaM}$ stimulates the NADPH-dependent reduction of cytochrome $c$ by NOS in a SOD-sensitive manner (500 units of SOD $\cdot \mathrm{ml}^{-1}$ ), suggesting that cytochrome $c$ reduction is mediated by intermediate superoxide [45]. However, others have found that NOS directly binds and reduces cytochrome $c$ in an SODinsensitive manner $[22,44]$ when using up to 1000 units of $\mathrm{SOD} \cdot \mathrm{ml}^{-1}$. In the present study, both the basal $\left(\mathrm{Ca}^{2+} / \mathrm{CaM}-\right.$ independent) and the CaM-dependent cytochrome $c$ reductase activities were SOD- as well as catalase-insensitive, arguing against a role for intermediate superoxide (and $\mathrm{H}_{2} \mathrm{O}_{2}$ ), similar to the NADPH-dependent cytochrome P450 reductase [22,53,54]. Furthermore, the lack of effect of SOD on basal cytochrome $c$ turnover indicates that the mechanisms of cytochrome $c$ reduction are similar in the presence and absence of $\mathrm{Ca}^{2+} / \mathrm{CaM}$.

Conversely, the MTS reductase activity of NOS was, at least in part, mediated by $\mathrm{O}_{2}^{-}$but not by $\mathrm{H}_{2} \mathrm{O}_{2}$. Based on our results, approximately half of the NOS-catalysed MTS reduction was mediated by direct transfer of electrons to MTS, fulfilling the definition of an NADPH diaphorase reaction, whereas the other half was reduced by NOS-derived superoxide anions. In the case of the NADPH diaphorase histochemical stain, the latter reaction might be excluded because of the presence of SOD in neuronal cells, thus resulting in the apparently uniform behaviour of this reaction in situ. This may also explain why PHS-72 is a more effective inhibitor of the NADPH diaphorase histochemical reaction when compared with the MTS reductase activity of purified NOS.

Recently, the concept of a stoichiometric redox role for $\mathrm{H}_{4} \mathrm{Bip}$ $[18,55]$ in catalytically active NOS has been put forward. The intermediate formation of $\mathrm{H}_{3} \mathrm{Bip}^{\circ}$, yet with almost full recovery of $\mathrm{H}_{4} \mathrm{Bip}$, requires that $\mathrm{H}_{4} \mathrm{Bip}$ is recycled by an intrinsic reductase activity. This reductase activity should occur independently of $\mathrm{Ca}^{2+} / \mathrm{CaM}$ (and at higher rates than $\mathrm{H}_{4}$ Bip consumption), and thus be different from $\mathrm{Ca}^{2+} / \mathrm{CaM}$-dependent oxygen activation by NOS. In order to clarify the role of enzyme-associated pterin or the NOS pterin binding site per se in the two reductase activities of NOS investigated, the effects of recently developed anti-pterins [31,32] on cytochrome $c$ and MTS reductase activities were tested (see Figure 4). PHS-32, a type I anti-pterin, which displaces $\geqslant 80 \%$ of the endogenously bound $\mathrm{H}_{4}$ Bip [30,31] without being a partial agonist itself, was without effect on MTS or on cytochrome $c$ turnover. This suggested that $\mathrm{H}_{4} \mathrm{Bip}$ neither has a direct role in the electron transfer leading to the reduction of MTS and cytochrome $c$ by native NOS-I nor does it compete with these substrates. However, a recent study detected an enzyme-bound $\mathrm{H}_{3} \mathrm{Bip}^{\circ}$-radical by EPR analysis [55]. A unifying hypothesis of both this and our findings [8] suggests that $\mathrm{H}_{4} \mathrm{Bip}$

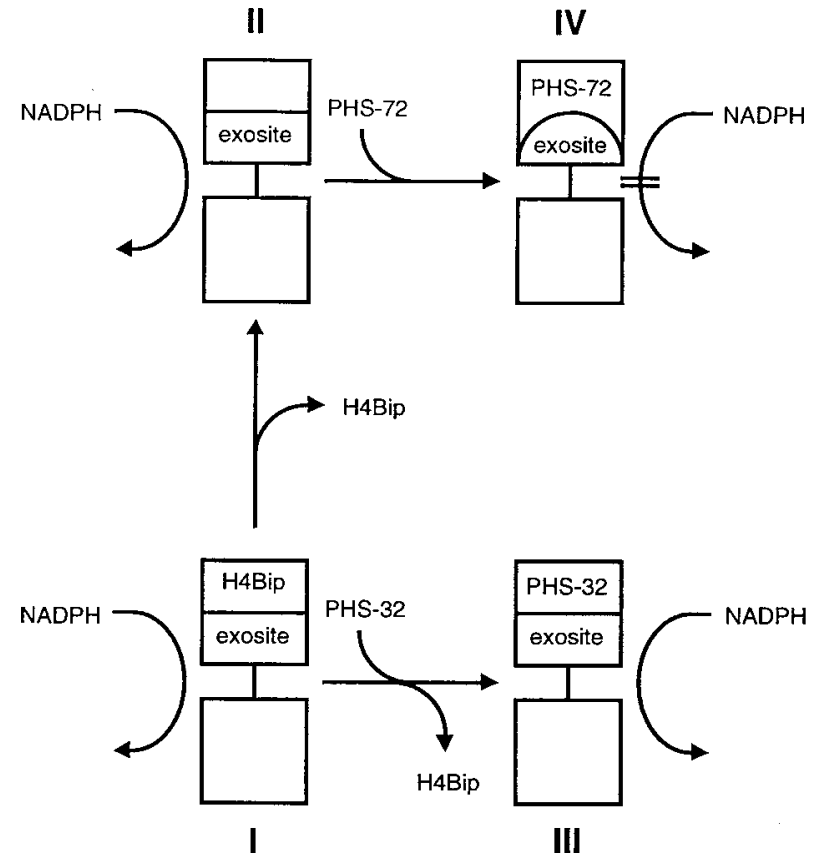

Scheme 1 Schematic representation of the effects of $\mathrm{H}_{4}$ Bip and antipterins on the reductase activities of NOS

$\mathrm{H}_{4}$ Bip-containing NOS monomers and dimers reduce cytochrome $c$, MTS and NBT by using NADPH as a source for electrons (I). These reductase activities remain intact after removing $\mathrm{H}_{4}$ Bip from the enzyme (II). The type I anti-pterin, PHS-32, replaces endogenously bound $\mathrm{H}_{4} \mathrm{Bip}$ from its binding site, but preserves the reductase activities of the enzyme (III). PHS-72, a type II anti-pterin, is unable to displace endogenously bound $\mathrm{H}_{4}$ Bip but binds to unoccupied pterin binding sites and the adjacent exosite of NOS. The latter is suggested to disrupt the electron flow of the enzyme, which is required for both reductase activities of NOS (IV).

is not necessarily involved in the electron flow and L-arginine turnover of the enzyme but helps in coupling NADPH oxidation to product formation ( $\mathrm{NO}$ and $\mathrm{H}_{2} \mathrm{O}_{2}$ instead of $\mathrm{NO}^{-}$and $\mathrm{O}_{2}^{-}$, in the presence or absence of $\mathrm{L}$-arginine respectively), resulting in the transient formation of a pterin radical.

PHS-72, a type II anti-pterin, does not readily displace endogenous $\mathrm{H}_{4}$ Bip. In analogy to NOS-I-catalysed L-arginine turnover, the inhibitory effect of PHS-72 seems to originate from possible conformational changes of the enzyme and/or blockade of an exosite by the bulky substituents at the C-6 and C-7 position of type II anti-pterins [31,32]. This structure-activity relationship was recently confirmed by comparative molecularfield analysis (H. Matter, W. Pfleiderer and H. H. H. W. Schmidt, unpublished work). Thus type II anti-pterins may disrupt electron flow from within the pterin binding pocket of the enzyme, without a need to interfere directly with endogenous $\mathrm{H}_{4} \mathrm{Bip}$ (Scheme 1). This might also explain the stronger effect of PHS72 on cytochrome $c$ versus MTS reduction. However, NOS reductase activities do not depend on protein-associated pterin, as both pterin-free monomers and pterin-containing dimers of recombinant human NOS-I expressed similar MTS and cytochrome $c$ reductase activities (see Table 2). Monomeric NOS may re-assemble to form dimeric enzyme, which is only functional for MTS/cytochrome $c$, but not for L-arginine conversion. However, this seems unlikely as neither L-arginine nor $\mathrm{H}_{4} \mathrm{Bip}$ were present in our incubation mixtures. In previous studies in our laboratory [30] and in other laboratories [47,56-58], redimerization of NOS monomers was not found in the absence of both L-arginine and $\mathrm{H}_{4} \mathrm{Bip}$. It is thus generally accepted that 
monomeric neuronal NOS absolutely depends on the presence of $\mathrm{L}$-arginine to form the dimeric enzyme. Reduction of MTS $\left(\mathrm{Ca}^{2+} / \mathrm{CaM}\right.$-independently) and of cytochrome $c\left(\mathrm{Ca}^{2+} / \mathrm{CaM}-\right.$ dependently) by monomeric NOS-I is in agreement with a previous study [58] reporting cytochrome $c$ reductase activity of monomeric NOS-II. Most interestingly, cytochrome $c$ reductase activity in monomeric NOS was also dependent on the presence of CaM. The CaM-binding site therefore seems to be intact in the NOS monomer, and electron flow can occur between the reductase and the oxygenase domains upon $\mathrm{Ca}^{2+} / \mathrm{CaM}$ binding.

We thus conclude that NOS displays distinct reductase activities with respect to their $\mathrm{Ca}^{2+} / \mathrm{CaM}$ dependence, SOD and anti-pterin sensitivity. In none of them does NOS-associated $\mathrm{H}_{4}$ Bip play a role. However, occupation of the NOS pterin binding site and adjacent exosite by the type-II PHS-72 interferes with the intrasubunit electron flux, possibly by affecting oxygenase/reductase coupling. With the resolution of the structure of the oxygenase domains of two NOS isoforms [18,21], anti-pterins will be a valuable tool to analyse further the $\mathrm{Ca}^{2+} / \mathrm{CaM}$-dependent coupling of this domain to the reductase site and intermediate $\mathrm{H}_{3} \mathrm{Bip}$ ' formation.

We thank Monika Weeger and Manfred Bernhardt for expert technical assistance, and Heinrich Hofmann, Lothar Fröhlich and Peter Kotsonis for helpful discussions. This work was supported by grants from the Bundesministerium für Bildung, Wissenschaft, Forschung und Technologie, the Fritz-Thyssen-Stiftung and the Deutsche Forschungsgemeinschaft (SFB 547/C7).

\section{REFERENCES}

1 Furchgott, R. F. and Vanhoutte, P. M. (1989) Endothelium-derived relaxing and contracting factors. FASEB J. 3, 2007-2018

2 Ignarro, L. J. (1991) Signal transduction mechanisms involving nitric oxide. Biochem. Pharmacol. 41, 485-490

3 Garthwaite, J. (1991) Glutamate, nitric oxide and cell-cell signalling in the nervous system. Trends Neurosci. 14, 60-67

4 Schmidt, H. H. H. W. and Walter, U. (1994) NO at work. Cell 78, 919-925

5 Nathan, C. and Hibbs, J. B. (1991) Role of nitric oxide synthesis in macrophage antimicrobial activity. Curr. Opin. Immunol. 3, 65-70

6 Förstermann, U., Gath, I., Schwarz, P., Closs, E. and Kleinert, H. (1995) Isoforms of nitric oxide synthase: properties, cellular distribution and expressional control. Biochem. Pharmacol. 50, 1321-1332

7 Schmidt, H. H. H. W., Hofmann, H., Schindler, U., Shutenko, Z. S., Cunningham, D. D. and Feelisch, M. (1996) No NO from NO synthase. Proc. Natl. Acad. Sci. U.S.A. 93, 14492-14497

8 Adak, S., Wang, Q. and Stuehr, D. J. (2000) Arginine coversion to nitroxide by tetrahydrobiopterin-free neuronal nitric-oxide synthase: implications for mechanism. J. Biol. Chem. 275, 33554-33561

9 Hobbs, A. J., Fukuto, J. M. and Ignarro, L. J. (1994) Formation of free nitric oxide from L-arginine by nitric oxide synthase: direct enhancement of generation by superoxide dismutase. Proc. Natl. Acad. Sci. U.S.A. 91, 10992-10996

10 Förstermann, U., Pollock, J. S., Schmidt, H. H. H. W., Heller, M. and Murad, F. (1991) Calmodulin-dependent endothelium-derived relaxing factor/nitric oxide synthase activity is present in the particulate and cytosolic fractions of bovine aortic endothelial cells. Proc. Natt. Acad. Sci. U.S.A. 88, 1788-1792

11 Busse, R. and Mülsch, A. (1990) Calcium-dependent nitric oxide synthesis in endothelial cytosol is mediated by calmodulin. FEBS Lett. 265, 133-136

12 Butt, E., Bernhardt, M., Smolenski, A., Kotsonis, P., Fröhlich, L. G., Sickmann, A., Meyer, H. E., Lohmann, S. M. and Schmidt, H. H. H. W. (2000) Endothelial nitricoxide synthase (Type III) is activated and becomes calcium independent upon phosphorylation by cyclic nucleotide-dependent protein kinases. J. Biol. Chem. 275, 5179-5187

13 Dimmeler, S., Fleming, I., Fisslthaler, B., Herrmann, C., Busse, R. and Zeiher, A. M. (1999) Activation of nitric oxide synthase in endothelial cells by Akt-dependent phosphorylation. Nature (London) 399, 601-605

14 Fulton, D., Gratton, J. P., McCabe, T. J., Fontana, J., Fujio, Y., Walsh, K., Franke, T. F., Papapetropoulos, A. and Sessa, W. C. (1999) Regulation of endothelium-derived nitric oxide production by the protein kinase Akt. Nature (London) 399, 597-601

15 Nathan, C. and Xie, Q.-W. (1994) Nitric oxide synthases: roles, tolls, and controls. Cell 78, 915-918
16 Schmidt, H. H. H. W., Pollock, J. S., Nakane, M., Gorsky, L. D., Förstermann, U. and Murad, F. (1991) Purification of a soluble isoform of guanylyl cyclase-activating-factor synthase. Proc. Natl. Acad. Sci. U.S.A. 88, 365-369

17 Stuehr, D. J. and Ikeda-Saito, M. (1992) Spectral characterization of brain and macrophage nitric oxide synthases. Cytochrome P-450-like haemproteins that contain a flavin semiquinone radical. J. Biol. Chem. 267, 20547-20550

18 Raman, C. S., Li, H., Martasek, P., Kral, V., Masters, B. S. S. and Poulos, T. L. (1998) Crystal structure of constitutive endothelial nitric oxide synthase: A paradigm for pterin function involving a novel metal center. Cell 95, 939-950

19 Nathan, C. (1992) Nitric oxide as a secretory product of mammalian cells. FASEB J. 6. 3051-3064

20 Knowles, R. G. and Moncada, S. (1994) Nitric oxide synthases in mammals. Biochem. J. 298, 249-258

21 Siddhanta, U., Presta, A., Fan, B., Wolan, D., Rousseau, D. L. and Stuehr, D. J. (1998) Domain swapping in inducible nitric-oxide synthase. Electron transfer occurs between flavin and heme groups located on adjacent subunits in the dimer. J. Biol. Chem. 273, 18950-18958

22 Klatt, P., Heinzel, B., John, M., Kastner, M., Böhme, E. and Mayer, B. (1992) $\mathrm{Ca}^{2+} /$ calmodulin-dependent cytochrome $c$ reductase activity of brain nitric oxide synthase. J. Biol. Chem. 267, 11374-11378

23 Hope, B. T., Michael, G. J., Knigge, K. M. and Vincent, S. R. (1991) Neuronal NADPH diaphorase is a nitric oxide synthase. Proc. Natl. Acad. Sci. U.S.A. 88, 2811-2814

24 Kharazia, V. N., Schmidt, H. H. H. W. and Weinberg, R. J. (1994) Type I nitric oxide synthase fully accounts for NADPH-diaphorase in rat striatum, but not cortex. Neuroscience 62, 983-987

25 Schmidt, H. H. H. W., Smith, R. M., Nakane, M. and Murad, F. (1992) $\mathrm{Ca}^{2+} /$ Calmodulin-dependent NO synthase type I: a biopteroflavoprotein with $\mathrm{Ca}^{2+} / \mathrm{calmodulin-independent} \mathrm{diaphorase} \mathrm{and} \mathrm{reductase} \mathrm{activities.} \mathrm{Biochemistry}$ 31, 3243-3249

26 Goodwin, C. J., Holt, S. J., Downes, S. and Marshall, N. J. (1995) Microculture tetrazolium assays: a comparison between two new tetrazolium salts, XTT and MTS J. Immunol. Methods 179, 95-103

27 Cory, A. H., Owen, T. C., Barlstrop, J. A. and Cory, J. G. (1991) Use of an aqueous soluble tetrazolium/formazan assay for cell growth assays in culture. Cancer Commun. 3, 207-212

28 Kwon, N. S., Nathan, C. F. and Stuehr, D. J. (1989) Reduced biopterin as a cofactor in the generation of nitrogen oxides by murine macrophages. J. Biol. Chem. 264, 20496-20501

29 Tayeh, M. A. and Marletta, M. A. (1989) Macrophage oxidation of L-arginine to nitric oxide, nitrite, and nitrate: tetrahydrobiopterine is required as a cofactor. J. Biol. Chem. 264, 19654-19658

30 Reif, A., Fröhlich, L. G., Kotsonis, P., Frey, A., Bömmel, H. M., Wink, D. A., Pfleiderer, W. and Schmidt, H. H. H. W. (1999) Tetrahydrobiopterin inhibits monomerization and is consumed during catalysis in neuronal NO synthase. J. Biol. Chem. 274, $24921-24929$

31 Bömmel, H. M., Reif, A., Fröhlich, L. G., Frey, A., Hofmann, H., Marecak, D. M., Groehn, V., Kotsonis, P., La, M., Köster, S. et al. (1998) Anti-pterins as tools to characterize the function of tetrahydrobiopterin in NO synthase. J. Biol. Chem. 273, 33142-33149

32 Fröhlich, L. G., Kotsonis, P., Traub, H., Taghavi-Moghadam, S., Al-Masoudi, N., Hofmann, H., Strobel, H., Matter, H., Pfleiderer, W. and Schmidt, H. H. H. W. (1999) Inhibition of neuronal nitric oxide synthase by 4-amino pteridine derivatives: structure-activity relationship of antagonists of $(6 R)$-5,6,7,8-tetrahydrobiopterin cofactor. J. Med. Chem. 42, 4108-4121

33 Mayer, B., John, M. and Böhme, E. (1990) Purification of a $\mathrm{Ca}^{2+} / \mathrm{cal}_{\text {modulin- }}$ dependent nitric oxide synthase from porcine cerebellum. Cofactor-role of tetrahydrobiopterin. FEBS Lett. 277, 215-219

34 Hofmann, H. and Schmidt, H. H. H. W. (1995) Thiol-dependence of nitric oxide synthase. Biochemistry $\mathbf{3 4}, 13443-13452$

35 Nakane, M., Pollock, J. S., Klinghofer, V., Basha, F., Marsden, P. A., Hokari, A. Ogura, T., Esumi, H. and Carter, G. W. (1995) Functional expression of three isoforms of human nitric oxide synthase in baculovirus-infected insect cells. Biochem. Biophys. Res. Commun. 206, 511-517

36 Bredt, D. S. and Snyder, S. H. (1990) Isolation of nitric oxide synthase, a calmodulinrequiring enzyme. Proc. Natt. Acad. Sci. U.S.A. 87, 682-685

37 Valtschanoff, J. G., Weinberg, R. J., Kharazia, V. N., Nakane, M. and Schmidt, H. H. H. W. (1993) Neurons in rat hippocampus that synthesize nitric oxide. J. Comp. Neurol. 331, 111-121

38 Valtschanoff, J. G., Weinberg, R. J., Kharazia, V. N., Schmidt, H. H. H. W., Nakane, M. and Rustioni, A. (1993) Neurons in rat cerebral cortex that synthesize nitric oxide: NADPH diaphorase histochemistry, NOS histochemistry, and colocalization with GABA. Neurosci. Lett. 157, 157-161 
39 Valtschanoff, J. G., Weinberg, R. J. and Rustioni, A. (1992) NADPH diaphorase in the spinal cord of rats. J. Comp. Neurol. 321, 209-222

40 Valtschanoff, J. G., Weinberg, R. J., Rustioni, A. and Schmidt, H. H. H. W. (1992) Nitric oxide synthase and GABA colocalize in lamina II of rat spinal cord. Neurosci. Lett. 148, 6-10

41 Saito, S., Kidd, G. J., Trapp, B. D., Dawson, T. M., Bredt, D. S., Wilson, D. A., Traystman, R. J., Snyder, S. H. and Hanley, D. F. (1994) Rat spinal cord neurons contain nitric oxide synthase. Neuroscience $\mathbf{5 9}, \mathbf{4 4 7 - 4 5 6}$

42 Dun, N. J., Dun, S. L., Wu, S. Y., Förstermann, U., Schmidt, H. H. H. W. and Tseng, L. F. (1993) Nitric oxide synthase immunoreactivity in the rat, mouse, cat and squirrel monkey spinal cord. Neuroscience $\mathbf{5 4}, 845-857$

43 Bradford, M. M. (1976) A rapid and sensitive method for the quantitation of microgram quantities of protein utilizing the principle of protein-dye binding. Anal. Biochem. 72, 248-254

44 Mayer, B., Heinzel, B., Klatt, P., John, M., Schmidt, K. and Böhme, E. (1992) Nitric oxide synthase-catalyzed activation of oxygen and reduction of cytochromes: reaction mechanisms and possible physiological implications. J. Cardiovasc. Pharmacol. 20, S54-S56

45 Sheta, E. A., McMillan, K. and Masters, B. S. S. (1994) Evidence for a bidomain structure of constitutive cerebellar nitric oxide synthase. J. Biol. Chem. 269, 15147-15153

46 Klatt, P., Schmidt, K., Lehner, D., Glatter, O., Bächinger, H. P. and Mayer, B. (1995) Structural analysis of porcine brain nitric oxide synthase reveals a role for tetrahydrobiopterin and L-arginine in the formation of an SDS-resistent dimer. EMBO J. 14, 3687-3695

47 Presta, A., Siddhanta, U., Chaoqun, W., Sennequir, N., Huang, L., Abu-Soud, H., Erzurum, A. and Stuehr, D. (1997) Comparative functions of dihydro- and tetrahydropterins in supporting electron transfer, catalysis and subunit dimerization in inducible nitric oxide synthase. Biochemistry 37, 298-310

48 Bredt, D. S., Glatt, C. E., Hwang, P. M., Fotuhi, M., Dawson, T. M. and Snyder, S. H. (1991) Nitric oxide synthase protein and mRNA are discretely localized in neuronal populations of the mammalian CNS together with NADPH diaphorase. Neuron 7, $615-624$

Received 2 January 2001; accepted 6 March 2001
49 Dawson, T. M., Bredt, D. S., Fotuhi, M., Hwang, P. M. and Snyder, S. H. (1991) Nitric oxide synthase and neuronal NADPH diaphorase are identical in brain and peripheral tissues. Proc. Natl. Acad. Sci. U.S.A. 88, 7797-7801

50 Abu-Soud, H. M. and Stuehr, D. J. (1993) Nitric oxide synthases reveal a role for calmodulin in controlling electron transfer. Proc. Natl. Acad. Sci. U.S.A. 90 10769-10772

51 Abu-Soud, H. M., Yoho, L. L. and Stuehr, D. J. (1994) Calmodulin controls neuronal nitric-oxide synthase by a dual mechanism. Activation of intra- and interdomain electron transfer. J. Biol. Chem. 269, 32047-32050

52 Kotsonis, P., Frohlich, L. G., Shutenko, Z. V., Horejsi, R., Pfleiderer, W. and Schmidt, H. H. H. W. (2000) Allosteric regulation of neuronal nitric oxide synthase by tetrahydrobiopterin and suppression of auto-damaging superoxide. Biochem. J. 346, 767-776

53 Iyanagi, T. and Mason, H. S. (1973) Some properties of hepatic reduced nicotinamide adenine dinucleotide phosphate-cytochrome $c$ reductase. Biochemistry 12, 2297-2308

54 Vermilion, J. L. and Coon, M. J. (1974) Highly purified detergent-solubilized NADPHcytochrome P-450 reductase from phenobarbital-induced rat liver microsomes. Biochem. Biophys. Res. Commun. 60, 1315-1322

55 Hurshman, A. R., Krebs, C., Edmondson, D. E., Huynh, B. H. and Marletta, M. A. (1999) Formation of a pterin radical in the reaction of the heme domain of inducible nitric oxide synthase with oxygen. Biochemistry 38, 15689-15696

56 Abu-Soud, H. M., Loftus, M. and Stuehr, D. J. (1995) Subunit dissociation and unfolding of macrophage no synthase: relationship between enzyme structure prosthetic group binding and catalytic function. Biochemistry 34, 11167-11175

57 Tzeng, E., Billiar, T. T., Robbins, P. D., Loftus, M. and Stuehr, D. J. (1995) Expression of human inducible nitric oxide synthase in a tetrahydrobiopterin (H4B)deficient cell line: H4B promotes assembly of enzyme subunits into an active dimer. Proc. Natl. Acad. Sci. U.S.A. 92, 11771-11775

58 Baek, K. J., Thiel, B. A., Lucas, S. and Stuehr, D. J. (1993) Macrophage nitric oxide synthase subunits: Purification, characterization, and the role of prosthetic groups and substrate in regulating their association into a dimeric enzyme. J. Biol. Chem. 268, 21120-21129 